\title{
Malaria resistance genes are associated with the levels of lgG subclasses directed against Plasmodium falciparum blood-stage antigens in Burkina Faso
}

\author{
Sarwat Afridi ${ }^{1,2}$, Alexandre Atkinson ${ }^{1,2}$, Séverine Garnier ${ }^{1,2}$, Francis Fumoux ${ }^{2,3}$ and Pascal Rihet ${ }^{1,2^{*}}$
}

\begin{abstract}
Background: $H B B, I L 4, I L 12, T N F, L T A, N C R 3$ and FCGR2A polymorphisms have been associated with malaria resistance in humans, whereas cytophilic immunoglobulin $\mathrm{G}(\mathrm{lgG})$ antibodies are thought to play a critical role in immune protection against asexual blood stages of the parasite. Furthermore, HBB, IL4, TNF, and FCGR2A have been associated with both malaria resistance and lgG levels. This suggests that some malaria resistance genes influence the levels of IgG subclass antibodies.

Methods: In this study, the effect of HBB, IL4, IL12, TNF, LTA, NCR3 and FCGR2A polymorphisms on the levels of IgG responses against Plasmodium falciparum blood-stage extract was investigated in 220 individuals living in Burkina Faso. The Pearson's correlation coefficient among lgG subclasses was determined. A family-based approach was used to assess the association of polymorphisms with anti-P. falciparum lgG, lgG1, lgG2, lgG3 and lgG4 levels.

Results: After applying a multiple test correction, several polymorphisms were associated with lgG subclass or lgG levels. There was an association of i) haemoglobin $C$ with IgG levels; ii) the FcyRlla H/R131 with IgG2 and IgG3 levels; iii) TNF-863 with IgG3 levels; iv) TNF-857 with IgG levels; and, v) TNF1304 with lgG3, IgG4, and IgG levels.

Conclusion: Taken together, the results support the hypothesis that some polymorphisms affect malaria resistance through their effect on the acquired immune response, and pave the way towards further comprehension of genetic control of an individual's humoral response against malaria.
\end{abstract}

Keywords: HBB, Immune genes, Plasmodium falciparum, Malaria, IgG subclass, Family-based association

\section{Background}

Plasmodium falciparum malaria is a major cause of worldwide mortality and morbidity. Host genetic factors have been shown to influence malaria infection intensity and clinical malaria. Several candidate genes have been associated with resistance against severe malaria, whereas linkage or association analyses mapped several loci controlling mild malaria and/or parasitemia [1]. Noticeably, chromosomes 5q31-q33 and 6p21-p23 have been linked to parasitaemia or mild malaria [2,3], whereas genes located within those chromosomal regions have been

\footnotetext{
* Correspondence: pascal.rihet@univ-amu.fr

'UMR1090 TAGC, INSERM, Marseille, F-13288, France

${ }^{2}$ Aix-Marseille University, Marseille F-13288, France

Full list of author information is available at the end of the article
}

associated with parasitaemia, mild or severe malaria [4-10]. The $H B B$ locus has been shown to be a major locus based on a genome association study for severe malaria, whereas haemoglobin $\mathrm{S}(\mathrm{HbS})$ and haemoglobin $\mathrm{C}(\mathrm{HbC})$ have been associated with protection against mild and severe malaria in a large number of studies. It should be stressed that a limited number of genes have been associated with mild or severe malaria in several independent studies; these include FCGR2A that encodes the human IgG receptor FcyRIIa.

Anti-P. falciparum IgG antibodies are thought to play a critical role in immune protection against asexual blood stages of the parasite. Passive transfer of IgG has provided protection against the $P$. falciparum blood stages in humans. In vitro, human IgGs that recognize 
either infected erythrocytes or merozoites act in cooperation with monocytes to eliminate the parasite [11]. Cytophilic IgGs that activate effector cells are, therefore, considered protective, while non-cytophilic IgGs against the same epitope may block the protective effect of the cytophilic ones. This hypothesis has been supported by several immune-epidemiological studies. High levels of the cytophilic IgG3 subclass have been associated with reduced parasitaemia, and protection against mild and severe malaria $[12,13]$. Interestingly, high levels of IgG2 could be correlated with protection in individuals carrying the H131 variant of monocytes FcyRIIa receptor, which efficiently binds to IgG2. In contrast, high levels of non-cytophilic IgG4 antibodies have been associated with susceptibility to malaria [14]. In this context, several investigators have provided evidence of the genetic control of IgG levels. Twin studies have shown a better concordance in monozygotic twins than in dizygotic twins for IgG levels [15]. In addition, high sib-sib correlations for IgG subclass levels have been detected [16-18]. Further evidence of a genetic component has been provided by a survey conducted in several sympatric ethnic groups having different genetic backgrounds [19]. Some candidate genes have been associated with IgG or IgG subclass levels. These include $H B B, I L 4, T N F$, and FCGR2A, which have also been associated with both malaria resistance and IgG levels [1,20-25]. This suggests that those genes control the production of cytophilic IgG subclasses. More generally, genes that have been associated with malaria resistance may be associated with the level of protective IgG subclasses. The linkage or association of HBB, IL4, IL12, TNF, LTA, and NCR3 with mild malaria or parasitaemia has been previously reported in a population living in Burkina Faso $[2,3,6,9,10,26]$. The objective of this study was to determine the influence of $H B B, I L 4, I L 12$, TNF, LTA, NCR3 and FCGR2A polymorphisms on the IgG subclass patterns of antibodies against $P$. falciparum antigens in the same population by using a family-based approach.

\section{Methods}

\section{Subjects, clinical diagnosis, and parasitological data}

The study population consisted of 220 individuals belonging to 34 families living in urban district of Bobo Dioulasso in Burkina Faso, in which infected mosquitoes were detected only during August, September and October; the numbers of infective bites per person and per year was 30. Blood samples were taken from individuals in July at the end of the dry season (P1) and in December at the end of rainy season (P2). The mean age of sibs was $12.1+6.2$ years (range one to 34 years). The study population and the area of parasite exposure have been described elsewhere [14,27]. Phenotypes and DNA were available for all the individuals. The Medical Authority of Burkina Faso approved the study protocol. Informed consent for multiple immunoparasitological and clinical surveys was obtained individually from all participants.

Febrile episodes were extensively recorded by active case detection during 24 months. For patients with fever, a thick blood film was prepared by the standard procedures. Diagnosis of mild malaria attack was based on P. falciparum parasitaemia, fever (axillary temperature more than $37.5^{\circ} \mathrm{C}$ ) and clinical symptoms (headache, aching, vomiting or diarrhoea in the children); in that case no threshold of parasitaemia was used. In the absence of classical symptoms of malaria, and once others pathologies could not be eliminated, only children (age $<15$ years) with more than 5,000 parasites per $\mathrm{ml}$ and older subjects with more than 2,000 parasites per $\mathrm{ml}$ were considered as having had a malaria attack. Each episode of illness was treated according to the recommendation of the CNRFP (Centre National de Recherche et Formation sur le Paludisme) of Burkina Faso. Parasitaemia was checked at the end of the treatment. Subjects who presented at least one mild malaria attack during the survey were considered in the analysis affected, while the others were considered unaffected.

Determination of parasitaemia was described in a previous study [26]. Briefly, each family was visited 20 times during the 24 months of the study, and parasitaemia was measured. In addition, parasitaemia was measured during febrile episodes. The mean number of parasitaemia measurements per subject was 15.2+5.1 (range 1-24) Fingerprint peripheral blood samples were taken from all family members present and thick and thin blood films were stained with Giemsa. The parasite determination and numeration were established blindly from two independent readings. Only P. falciparum asexual forms were retained to determine parasitaemia. Parasitaemia was defined as the number of parasitized erythrocytes observed per $\mu \mathrm{l}$ in thin blood films.

Maximum parasitaemia was based on a logarithmic transformation of the highest parasitaemia that was measured in each individual during the survey [26]. Mean of adjusted asymptomatic parasitaemia was a logarithmic transformation of the parasitaemia adjusted for seasonal transmission [26], after excluding parasitaemia during febrile episodes. To take into account the seasonality of the transmission, the influence of the date of the visits on $\ln (1+$ parasitaemia) (LP) was evaluated by one way analysis of variance. The mean LP observed during each visit was calculated. The individual LP was then corrected for the visit effect by subtracting from each individual LP the mean LP of the corresponding visit.

Since age influenced mild malaria attack, maximum parasitaemia, and the mean of adjusted parasitaemia, the age effect was further taken into account. Linear regression was carried out to calculate the residual for 
maximum parasitaemia and the mean of adjusted parasitaemia, whereas logistic regression was used to calculate the residual for mild malaria. The residuals were used as phenotypes for linkage and association analyses.

\section{IgG sub-class phenotype determination}

The measurements of IgG subclasses directed against P. falciparum blood-stage extracts were previously performed; the data sets previously reported was used [14]. Briefly, the P. falciparum W2 strain (Southeast Asia) was maintained and synchronized. Schizonts were isolated from infected red blood cells based on a treatment with saponin, were sonicated on ice in phosphate-buffered saline containing protease inhibitors. Sonicates were centrifuged, and the supernatants were filtered through a $0.22 \mu \mathrm{m}$-pore-size membrane, and were aliquoted and stored at $-70^{\circ} \mathrm{C}$ until use. Enzyme-linked immunosorbent assay (ELISA) plates (Nunc) were coated with $1 \mu \mathrm{g}$ of $P$. falciparum extract $/ \mathrm{ml}$ in sodium carbonate buffer $(100 \mathrm{mM}, \mathrm{pH}$ 9.6). Plates were saturated with $3 \%$ bovine serum albumin in phosphate-buffered saline. Serum dilutions were incubated for $16 \mathrm{~h}$ at $4{ }^{\circ} \mathrm{C}$ (1:20 for IgG2 and IgG4, 1:100 for IgG1 and IgG3, and 1:400 for IgG). The following monoclonal antibodies were used: anti-IgG1 (clone 8c/6-39; The Binding Site), IgG2 and IgG3 (clone HP 6002 and HP 6050; Clinisciences), and IgG4 (clone RJ4; Immunotech). Total IgG was detected using a goat $\mathrm{F}(\mathrm{ab} /)_{2}$ anti-human IgG (Jackson Laboratories). The anti-IgG1 and -IgG were conjugated to alkaline phosphatase, the anti-IgG2 and -IgG3 were biotinylated, and the anti-IgG4 was unlabelled. $\mathrm{F}(\mathrm{ab} /)_{2}$ anti-mouse IgG conjugated to alkaline phosphatase was used for IgG4 detection. Signal amplification was performed for IgG2 and IgG3 detection by using streptavidin and biotinylated alkaline phosphatase (Pierce); the sensitivity of the assay was 30 -fold higher than that of the assay using the same monoclonal antibodies conjugated to alkaline phosphatase. After $2 \mathrm{~h}$ of incubation at room temperature, enzymatic activities were revealed by $p$-nitrophenyl phosphate (Sigma) $(1 \mathrm{mg} / \mathrm{ml})$ in Tris buffer (pH 9.6). The optical densities were read at $405 \mathrm{~nm}$ using a DIAS automatic plate reader (Dynex Technology). A pool of 200 sera equally diluted was used to draw a standard curve; the same serum pool was used for IgG, IgG1, IgG2, IgG3 and IgG4 measurements. Fifty samples that were randomly selected were titrated; the titration curves were parallel to the standard curve for each IgG subclass. All tests were done in duplicate, and antibody levels were calculated by using the standard curve and were expressed as arbitrary units (AU). To allow for zero values in further analyses, a logarithmic transformation was applied based on $\log (1+\mathrm{AU})$ (LAU) to the AU. The mean LAU and standard deviation were calculated at P1 and at P2. To correct the individual LAU for the visit effect, the LAU was standardized at P1 and at P2, and the mean of adjusted LAU (MALAU) was calculated for each subject, as previously described. The influence of age and sex on MALAU was further evaluated using polynomial regression; the age was considered as a continuous variable. There was an effect of age on IgG subclass and IgG levels $(P<0.01)$, whereas there was no influence of sex. Age was retained for adjustment for each IgG subclass. The residual was the phenotype used in the statistical analyses. IgG, IgG1, IgG2, IgG3 and IgG4 phenotypes were calculated for 193 individuals.

\section{Genotyping}

Blood samples were taken by venipuncture. The haemoglobin genotypes were identified by electrophoresis of red blood cell lysates on acetate membrane at an alkaline $\mathrm{pH}$. Acetate sheets were stained with Ponceau red. This yielded discrimination of haemoglobin $\mathrm{A}(\mathrm{HbA}), \mathrm{S}(\mathrm{HbS})$ and $\mathrm{C}(\mathrm{HbC})$.

DNA was extracted from mononuclear cells separated by the Ficoll-Hypaque density gradient as described [27]. Samples were first subject to prior whole-genome amplification by primer extension pre-amplification [28]. For IL4, FCGR2A, NCR3, TNF, LTA, and IL12B polymorphisms, the data sets previously reported were used $[6,9,10,29,30]$. Briefly, genotypes for NCR3, TNF, LTA, and IL12B polymorphisms have been obtained by sequencing with a CEQ 8000 automated fluorescent sequencer (Beckman Coulter, Roissy CDG, France), whereas FCGR2A H/R131 genotypes was determined by using PCR and allele-specific restriction enzyme digestion methods as previously described [31]. The call rate was higher than $88 \%$ for all the polymorphisms, based on the 193 individuals, for which the IgG subclass levels have been measured; the median call rate was $94 \%$.

\section{Statistical analyses}

The correlation among IgG subclasses was evaluated using Pearson's correlation coefficient. In addition, combined association and linkage analyses were carried out using the family-based association test (FBAT) approaches [32]. The FBAT statistics, which use data from sibships in nuclear families, takes into account sibling correlations. The default null hypothesis is no linkage or no association and the statistics under this hypothesis calculates the distribution of offspring genotypes that are conditional on parental genotypes and on trait values. FBAT calculates a $\mathrm{Z}$ score and a two-side $\mathrm{P}$ value based on normal distribution. Multiple test corrections was further performed using the false discovery rate (FDR) method for all the statistical tests [33]; an FDR of $10 \%$ was carried out. 


\section{Results}

Table 1 presents the summary of the correlation between IgG sub-class levels. There were significant positive correlations between all measured IgG subclasses $(P<0.0001)$. In particular, IgG1 and IgG3 levels were highly correlated $(\mathrm{r}=0.631)$. The best correlations were between IgG levels and IgG1 levels on the one hand and IgG levels and IgG3 levels on the other hand $(r>0.7)$.

Allele frequencies for all single-nucleotide polymorphisms (SNPs) and previously reported family-based associations with parasitaemia and mild malaria are shown in Table 2 and Additional file 1, respectively. Additional file 1 also shows the family-based associations of SNPs with parasitaemia and mild malaria in individuals $(n=193)$, for which the level of IgG subclasses has been measured. $\mathrm{HbC}, \quad L T A+80, \quad T N F-1031, \quad T N F-238, \quad T N F 1304$, and NCR3-412 were associated with parasitaemia or mild malaria in this sub-population (Additional file 1). Moreover, FcyRIIa H/R131 was associated with mild malaria in individuals, for which the level of IgG2 was higher than the median (Additional file 1).

The family-based association of SNPs with the level of IgG subclasses (IgG1, IgG2, IgG3, and IgG4) and IgG against P. falciparum crude extract was further assessed. The additive, the dominant, and the recessive models were used for each SNP. The FBAT analysis gave a number of significant results at the nominal level of 0.05, although there was no association of $\mathrm{HbS}, I L 12 B$ pro, and IL12B 3' UTR, IL4-590, NCR3-412, NCR3-3790, TNF238, TNF-308, and TNF-1031 polymorphisms with the IgG responses (Tables 2 and 3). After correcting for multiple tests, there were only some SNPs that were significantly associated with anti-malarial IgG subclass levels, as shown in Tables 2 and 3. The most significant finding was a positive association between IgG2 levels and FcyRIIa H131 based on a recessive model. Conversely, IgG3 levels were negatively associated with FcyRIIa $\mathrm{H} 131$ based on a dominant model. $\mathrm{HbC}$ was positively associated with IgG levels based on an additive model. Three TNF polymorphisms were associated with IgG responses based on an additive model: TNF-863 and TNF-857 were associated with IgG3 levels and IgG

Table 1 Correlation between anti-malarial IgG subclass levels in individuals living in an endemic area in Burkina Faso

\begin{tabular}{lllll}
\hline & $\lg G 1$ & $\lg G 2$ & $\lg \mathbf{3} 3$ & $\lg \mathbf{3}$ \\
\hline $\lg G 1$ & 1 & & & \\
$\lg G 2$ & $0.373^{\mathrm{a}}$ & 1 & & \\
$\lg G 3$ & $0.631^{\mathrm{a}}$ & $0.558^{\mathrm{a}}$ & 1 & 1 \\
$\lg G 4$ & $0.467^{\mathrm{a}}$ & $0.326^{\mathrm{a}}$ & $0.46^{\mathrm{a}}$ & 1 \\
$\lg \mathrm{a}$ & $0.71^{\mathrm{a}}$ & $0.537^{\mathrm{a}}$ & $0.787^{\mathrm{a}}$ & $0.507^{\mathrm{a}}$ \\
\hline
\end{tabular}

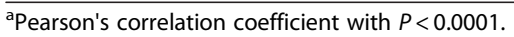

Table 2 Family-based association analyses for anti-Plasmodium falciparum IgG levels

\begin{tabular}{|c|c|c|c|}
\hline Locus & $\begin{array}{l}\text { SNP ID } \\
\text { number }\end{array}$ & $\begin{array}{l}\text { Allele }^{a} \\
\left(A F^{b}\right)\end{array}$ & $P^{c}$ \\
\hline IL12Bpro (promoter) & rs17860508 & $\begin{array}{l}\text { TTAGAG/GC } \\
(0.3068)\end{array}$ & $P>0.05$ \\
\hline IL12B (3'UTR) & rs3212227 & $A / C(0.3275)$ & $P>0.05$ \\
\hline IL4-590 (promoter) & rs2243250 & $\mathrm{C} / \mathrm{T}(0.8017)$ & $P>0.05$ \\
\hline FCGR2A H/R131 (exon 4) & rs1801274 & $C / T(0.5371)$ & $T^{d}\left(0.0166^{f}\right)$ \\
\hline$H b C$ (exon1) & rs33930165 & $A / C(0.1682)$ & $C^{d}\left(0.0091^{e, g}\right)$ \\
\hline HbS (exon1) & rs334 & $\mathrm{A} / \mathrm{T}(0.0193)$ & $P>0.05$ \\
\hline LTA + 80 (intron 1) & rs2239704 & C/A (0.3542) & $P>0.05$ \\
\hline TNF-1031(promoter) & rs1799964 & $\mathrm{T} / \mathrm{C}(0.1106)$ & $P>0.05$ \\
\hline TNF-863 (promoter) & rs1800630 & C/A (0.0858) & $A^{d}\left(0.0440^{e}\right)$ \\
\hline TNF-857 (promoter) & rs1799724 & $C / T(0.0228)$ & $\mathrm{T}^{\mathrm{d}}\left(0.0064^{\mathrm{e}, \mathrm{g}}\right)$ \\
\hline TNF-308 (promoter) & rs1800629 & $\mathrm{G} / \mathrm{A}(0.1063)$ & $P>0.05$ \\
\hline TNF-238 (promoter) & rs361525 & $\mathrm{G} / \mathrm{A}(0.0264)$ & $P>0.05$ \\
\hline TNF1304 (intron 3) & rs3093664 & $\mathrm{A} / \mathrm{G}(0.075)$ & $A^{d}\left(0.0083^{e, g}\right)$ \\
\hline NCR3-412 (promoter) & rs27362191 & $\mathrm{G} / \mathrm{C}(0.2267)$ & $P>0.05$ \\
\hline NCR3*3790 (3'UTR) & rs986475 & $\mathrm{T} / \mathrm{C}(0.0272)$ & $C^{d}\left(0.0307^{e}\right)$ \\
\hline
\end{tabular}

Abbreviations: HbC, Haemoglobin C; IL4, Interleukin 4; LTA, Lymphotoxin-a; AF, allele frequency; NCR3, Natural cytotoxicity receptor 3; SNP, Single-nucleotide polymorphism; TNF, Tumour necrosis factor; UTR, Untranslated region. aWild allele / variant allele.

${ }^{b}$ Variant allele frequency that was calculated in the study population. ${ }^{c}$ Chi-square test P-value for lgG levels.

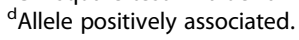

eAdditive model.

fominant model.

${ }^{9}$ Significant $\mathrm{P}$ value after applying a false discovery rate of $10 \%$.

levels, respectively, whereas TNF1304 was associated with IgG3, IgG4, and IgG levels.

\section{Discussion}

The aim of this study was to determine the effect of several candidate gene polymorphisms on the IgG subclass responses against $P$. falciparum extract in a population living in an endemic area in Burkina Faso. Most of the candidates have been associated with parasitaemia, mild or severe malaria [1].

There was positive correlation between all measured antibody levels. Anti-malarial IgG levels were correlated with all anti-malarial IgG subclasses. The best correlations were the correlations of anti-malarial IgG levels with anti-malarial IgG1 and IgG3 levels. A correlation between all anti-P. falciparum IgG subclass levels was observed, the best correlation being between IgG1 and IgG3 levels. The results are similar to a study in Thailand, where anti-malarial IgG3 levels were correlated to IgG1 and IgG2 levels [34]. The results are also coherent with a recent study conducted in Sudan, where antimalarial IgG levels were correlated with each antimalarial IgG subclass against malarial antigen, and 
Table 3 Family-based association analyses for anti-Plasmodium falciparum IgG subclass levels

\begin{tabular}{|c|c|c|c|c|}
\hline & $\operatorname{lgG} 1$ & $\operatorname{lgG} 2$ & $\lg G 3$ & $\operatorname{lgG} 4$ \\
\hline Locus & $P^{a}$ & $P^{a}$ & $P^{a}$ & $P^{a}$ \\
\hline IL12Bpro & $P>0.05$ & $P>0.05$ & $P>0.05$ & $P>0.05$ \\
\hline IL12B3'UTR & $P>0.05$ & $P>0.05$ & $P>0.05$ & $P>0.05$ \\
\hline IL4-590 & $P>0.05$ & $P>0.05$ & $C^{b}\left(0.0472^{d}\right)$ & $P>0.05$ \\
\hline FCGR2A H/R131 & $P>0.05$ & $\mathrm{~T}^{\mathrm{b}}\left(0.0003^{\mathrm{e}, f}\right)$ & $C^{b}\left(0.0010^{d, f}\right)$ & $P>0.05$ \\
\hline $\mathrm{HbC}$ & $P>0.05$ & $C^{b}\left(0.0139^{d}\right)$ & $P>0.05$ & $P>0.05$ \\
\hline $\mathrm{HbS}$ & $P>0.05$ & $P>0.05$ & $P>0.05$ & $P>0.05$ \\
\hline$L T A+80$ & $A^{b}\left(0.0305^{c}\right)$ & $A^{b}\left(0.0505^{c}\right)$ & $A^{b}\left(0.0214^{c}\right)$ & $A^{b}\left(0.0139^{c}\right)$ \\
\hline TNF-1031 & $P>0.05$ & $P>0.05$ & $P>0.05$ & $P>0.05$ \\
\hline TNF-863 & $A^{b}\left(0.0379^{c}\right)$ & $P>0.05$ & $A^{b}\left(0.0082^{c, f}\right)$ & $P>0.05$ \\
\hline TNF-857 & $P>0.05$ & $P>0.05$ & $\mathrm{~T}^{\mathrm{b}}\left(0.0413^{\mathrm{C}}\right)$ & $\mathrm{T}^{\mathrm{b}}\left(0.0249^{\mathrm{c}}\right)$ \\
\hline TNF-308 & $P>0.05$ & $P>0.05$ & $P>0.05$ & $P>0.05$ \\
\hline TNF-238 & $P>0.05$ & $P>0.05$ & $P>0.05$ & $P>0.05$ \\
\hline TNF1304 & $A^{b}\left(0.0495^{c}\right)$ & $P>0.05$ & $A^{b}\left(0.0099^{c, f}\right)$ & $A^{b}\left(0.0108^{c, f}\right)$ \\
\hline NCR3-412 & $P>0.05$ & $P>0.05$ & $P>0.05$ & $P>0.05$ \\
\hline$N C R 3^{*} 3790$ & $P>0.05$ & $P>0.05$ & $C^{b}\left(0.0276^{c}\right)$ & $C^{b}\left(0.0196^{c}\right)$ \\
\hline
\end{tabular}

Abbreviations: HbC, Haemoglobin C; lgG, Immunoglobulin G; IL4, Interleukin 4; LTA, Lymphotoxin-a; NCR3, Natural cytotoxicity receptor 3; P. falciparum, Plasmodium falciparum; TNF, Tumour necrosis factor.

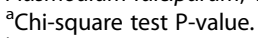

${ }^{\mathrm{b}}$ Allele positively associated.

cAdditive model.

${ }^{\mathrm{d}}$ Dominant model.

${ }^{\mathrm{e}}$ Recessive model.

fSignificant P value after applying a false discovery rate of $10 \%$.

where there was an age-dependent association of protective IgG2 and IgG3 subclasses [12,35]. Cytokines that are effective in most of IgG subclass production could partly explain the correlations between the IgG subclass levels. IL4 induces switching to $\epsilon, \gamma 1, \gamma 3, \gamma 4$ and also enhances the expression of $\epsilon, \gamma 1, \gamma 3$ and $\gamma 4$ germline transcript, and the secretion of corresponding proteins [36]. IL4-590 polymorphism does not explain, nevertheless, variation in the level of IgG subclasses, suggesting that other IL4 polymorphisms should be investigated. In addition, other cytokines, such as IL2, IL6, or IL10 are also known to enhance the IgG production in vitro by $\mathrm{B}$ cells activated by polyclonal activators or plasmodial antigens $[37,38]$. Besides, IL10, which causes the switch towards IgG1 and IgG3, likely explains the high correlation between IgG1 and IgG3 levels [39]. Interestingly, IgG2 and IgG3 levels were also strongly correlated, whereas the correlation between IgG1 and IgG2 levels was low. IFNgamma seems to inhibit IgG1 production in vitro, and to enhance IgG2 production [40]. Although IFN-gamma is unlikely an IgG2 switch factor, $\mathrm{T}$ cells producing IFNgamma, namely the Th1 (T helper 1 ) lymphocytes, have been shown to produce an IgG2 switch factor acting on CD40-activated naïve B cells [41]. These observations suggest that cytokines produced by Th1 lymphocytes may collectively increase the production of IgG2. In all, the correlations between IgG subclass levels encourage to further assess the production of cytokines in individual living in endemic areas.

The family-based associations of candidate polymorphisms on the IgG subclass levels were further investigated. There were some significant results after applying a multiple test correction. There was no association of IgG subclass levels with IL4 and IL12B polymorphisms, while others reported an association of anti-malarial IgG levels with IL4-590 [20]. There was no association between antimalarial IgG subclass levels and NCR3 polymorphisms, although those may alter the production of IFN-gamma by NK cells. The association of $L T A+80$ with all antimalarial IgG subclass levels was significant at the nominal level of $5 \%$, but was no more significant after applying a multiple test correction; this polymorphism may, nevertheless, require further investigation to confirm or invalidate the trend.

$\mathrm{HbS}$ and $\mathrm{HbC}$ have been associated with protection against mild and severe malaria, and it has been proposed that these polymorphisms could increase the elimination of the parasite through acquired immune mechanisms [42]. There was no association between $\mathrm{HbS}$ and antimalarial IgG responses, although other studies provided evidence for a positive association [21,22]. These conflicting results may be explained by the low frequency of $\mathrm{HbS}$ 
in the study population. In contrast, $\mathrm{HbC}$ that was negatively associated with maximum parasitemia and mild malaria was positively associated with anti-malarial $\operatorname{IgG}$ levels in the same population, further suggesting that $H B B$ polymorphisms alter the anti-malarial IgG production. This result is consistent with previous reports also providing evidence for an involvement of $\mathrm{HbC}$ in the immune response against infected erythrocytes through enhanced IgG production $[43,44]$. This further supports the hypothesis that the protection against malaria of $\mathrm{HbC}$ may be partly mediated by acquired immunity against malaria, more particularly by IgG-mediated effector mechanisms. Interestingly, there was also a trend for the production of anti-malarial IgG2 levels; although the association was not significant after applying a multiple test correction, this trend may require further attention in other populations.

The FcyRIIa H131 allele has been associated with protection from severe malaria in several populations [1]. Furthermore, it has been demonstrated to be the only receptor for IgG2, the high level of which have been associated with protection against $P$. falciparum malaria in a population living in Burkina Faso [14], and in other populations [45,46]. The FcyRIIa H131 allele has been found to be particularly prevalent in the Fulani, who are less affected by clinical malaria than individuals from other ethnic groups; interestingly, the Fulani also showed high levels of anti-malarial IgG2 [23,47]. On this basis, an effect of the FcyRIIa H131 allele on antimalarial IgG2 levels was anticipated in this study. The data provided evidence of a significant association of FcyRIIa H131 allele with IgG2 levels based on a recessive model. This family-based result is consistent with population-based results previously published [22,23]. Together, these observations indicate that the FcyRIIa H131 allele at the homozygous state increases the production of anti-malarial IgG2. In the same way, there is a trend for anti-malarial IgG levels based on a recessive model, suggesting that the FcyRIIa H131 allele at the homozygous state increases the production of antimalarial IgG, although the association was not significant after correcting for multiple tests. Thus, the FcyRIIa H131 allele may increase the phagocytosis by monocytes or macrophages, and may favour the antigen presentation by these cells to the $\mathrm{T}$ helper lymphocytes; this hypothesis remains to be assessed. Conversely, there was a negative association of the FcyRIIa H131 allele with anti-malarial IgG3 levels based on recessive model, suggesting that the FcyRIIa $\mathrm{H} 131$ allele at the homozygous state diminishes the level of anti-malarial IgG3. In the same way, Israelsson et al. found that the FcyRIIa R131 allele carriers in the Fulani had higher anti-malarial IgG3 levels than the individuals homozygous for the FcyRIIa H131 allele. One might speculate that more IgG3 will be present in the circulation of individuals with the Fc $\gamma$ RIIa R131 allele, because the Fc $\gamma$ RIIa H131 allele has a higher binding than the FcyRIIa R131 allele [48]. Nevertheless, the FcrRIIa H131 allele was associated with higher levels of anti-malarial IgG3 in another study in the Fulani [49]. It is likely that other factors affecting the production of IgG subclass antibodies, such as the cytokines or the antigens used, could partly explain the conflicting results [38].

In previous studies, TNF polymorphisms have been related to severe malaria. SNPs at position $-1031,-857$, $-308,-238$ and -863 in the promoter region of TNF gene exhibit differential associations to malaria and TNF production in different populations suggesting that individual TNF responses may be genetically determined [7,8,50,51]. TNF1304 within intron 3 was associated with variation in mild malaria and parasitaemia [10], and TNF-308A and TNF-238A allele have been associated with high anti-P. falciparum antibodies $[24,25]$. In this study, there was no association of IgG subclass levels with TNF-308 and TNF-238 polymorphisms. TNF-863A and TNF-857 $\mathrm{T}$ were, however, associated with high anti-malarial IgG3 and IgG levels, respectively. Moreover, there was an association of low IgG3, IgG4, and IgG levels with TNF1304, which has been associated with mild malaria and parasitaemia in the same population [10]; this further supports the role of TNF1304 on malaria phenotypes, although the effect of the polymorphism on the molecular function or the gene expression has not been reported. In contrast, the molecular effect of polymorphisms within the TNF promoter has been studied. Other authors reported that the transcription factor OCT-1 binds specifically to the $T N F-863 \mathrm{~A}$ and TNF-857 $\mathrm{T}$ alleles, that the transcriptional promoter activity of a haplotype harbouring TNF-863A and TNF-857 $\mathrm{T}$ was higher than the one of other haplotypes in Japan [50,51]. An explanation for association of TNF polymorphism with IgG response could be that TNF gene is important in the development of humoral response as an autocrine B-cell growth factor [52].

\section{Conclusions}

Our results indicate that $\mathrm{HbC}, T N F-857 \mathrm{~T}$, and TNF1304A were associated with high levels of antimalarial IgG. The FcyRIIa H131 allele was associated with high levels of anti-malarial IgG2 and low levels of anti-malarial IgG3. TNF-863A was associated with high levels of anti-malarial IgG3, whereas TNF1304 was associated with variation in the levels of anti-malarial IgG3 and IgG4. It should be stressed that all these polymorphisms have been associated with parasitaemia, mild malaria or severe malaria; this suggests that their protective effect may be partly due to their effect on the IgG subclass production. 


\section{Additional file}

Additional file 1: Family-based association of polymorphisms with parasitological and clinical phenotypes.

\section{Abbreviations}

FCGR2A: Fc-gamma Receptor IIA; FDR: False discovery rate; $\mathrm{HbC}$ : Haemoglobin C; HbS: Haemoglobin S; IL: Interleukin; IgG: immunoglobulin G; LTA: Lymphotoxin a; NCR3: Natural cytotoxicity receptor 3; P. falciparum: Plasmodium falciparum; TNF: Tumor necrosis factor; UTR: Untranslated region.

\section{Competing interests}

The authors declare that they have no conflicting interests.

\section{Authors' contributions}

SA calculated the IgG subclass phenotypes, evaluated the correlation between IgG subclass phenotypes, and carried out most of the FBAT analyses. AA and SG participated in the FBAT analyses, and the multiple test correction. FF participated in the design of the study, and revised the results and the manuscript. PR performed the design of the study, supervised the IgG phenotype determination and the statistical analyses, and wrote the manuscript. All authors read and approved the final manuscript.

\section{Acknowledgements}

We thank all volunteer families of Bobo Dioulasso. This work was supported by the 'Institut National de la Santé et de la Recherche Médicale' (INSERM). AA, SA and SG were supported by a studentship from the French Ministry of Research and Technology, from the Higher Education Commission (HEC) of Pakistan, and from the PACA regional council and INSERM, respectively.

\section{Author details}

1UMR1090 TAGC, INSERM, Marseille, F-13288, France. ${ }^{2}$ Aix-Marseille University, Marseille F-13288, France. ${ }^{3}$ UMR-MD3, Marseille F-13385, France.

Received: 22 June 2012 Accepted: 30 August 2012

Published: 4 September 2012

\section{References}

1. Kwiatkowski DP: How malaria has affected the human genome and what human genetics can teach us about malaria. Am J Hum Genet 2005, 77:171-192.

2. Flori L, Kumulungui B, Aucan C, Esnault C, Traoré AS, Fumoux F, Rihet P: Linkage and association between Plasmodium falciparum blood infection levels and chromosome 5q31-q33. Genes Immun 2003, 4:265-268.

3. Flori L, Sawadogo S, Esnault C, Delahaye NF, Fumoux F, Rihet P: Linkage of mild malaria to the major histocompatibility complex in families living in Burkina Faso. Hum Molec Genet 2003, 12:375-378.

4. Gyan BA, Goka B, Cvetkovic JT, Kurtzhals JL, Adabayeri V, Perlmann $H_{\text {, }}$ Lefvert AK, Akanmori BD, Troye-Blomberg M: Allelic polymorphisms in the repeat and promoter regions of the interleukin- 4 gene and malaria severity in Ghanaian children. Clin Exp Immunol 2004, 138:145-150.

5. Phawong C, Ouma C, Tangteerawatana P, Thongshoob J, Were T, Mahakunkijcharoen Y, Wattanasirichaigoon D, Perkins DJ, Khusmith S: Haplotypes of IL12B promoter polymorphisms condition susceptibility to severe malaria and functional changes in cytokine levels in Thai adults. Immunogenetics 2010, 62:345-356.

6. Barbier M, Delahaye NF, Fumoux F, Rihet P: Family-based association of a low producing lymphotoxin-alpha allele with reduced Plasmodium falciparum parasitemia. Microbes Infect 2008, 10:673-679.

7. Hananantachai H, Patarapotikul J, Ohashi J, Naka I, Krudsood S, Looareesuwan S, Tokunaga K: Significant association between TNF-alpha (TNF) promoter allele $(-1031 \mathrm{C},-863 \mathrm{C}$, and $-857 \mathrm{C})$ and cerebral malaria in Thailand. Tissue Antigens 2007, 69:277-280.

8. McGuire W, Knight JC, Hill AV, Allsopp CE, Greenwood BM, Kwiatkowski D: Severe malarial anemia and cerebral malaria are associated with different tumor necrosis factor promoter alleles. J Infect Dis 1999, 179:287-290.
9. Delahaye NF, Barbier M, Fumoux F, Rihet P: Association analyses of NCR3 polymorphisms with $P$. falciparum mild malaria. Microbes Infect 2007 9:160-166

10. Flori L, Delahaye NF, Iraqi FA, Hernandez-Valladares M, Fumoux F, Rihet P: TNF as a malaria candidate gene: polymorphism-screening and familybased association analysis of mild malaria attack and parasitemia in Burkina Faso. Genes Immun 2005, 6:472-480.

11. Bouharoun-Tayoun $H$, Oeuvray $C$, Lunel $F$, Druilhe $P$ : Mechanisms underlying the monocyte-mediated antibody-dependent killing of Plasmodium falciparum asexual blood stages. J Exp Med 1995, 182:409-418.

12. Giha HA, Nasr A, Iriemenam NC, Balogun HA, Arnot D, Theander TG, Troye-Blomberg M, Berzins K, ElGhazali G: Age-dependent association between IgG2 and IgG3 subclasses to Pf332-C231 antigen and protection from malaria, and induction of protective antibodies by sub-patent malaria infections, in Daraweesh. Vaccine 2010, 28:1732-1739

13. Roussilhon C, Oeuvray C, Müller-Graf C, Tall A, Rogier C, Trape J-F, Theisen M, Balde A, Pérignon J-L, Druilhe P: Long-term clinical protection from falciparum malaria is strongly associated with lgG3 antibodies to merozoite surface protein 3. PLoS Med 2007, 4:e320.

14. Aucan C, Traore Y, Tall F, Nacro B, Traore-Leroux T, Fumoux F, Rihet P: High immunoglobulin G2 (lgG2) and low lgG4 levels are associated with human resistance to Plasmodium falciparum malaria. Infect Immun 2000, 68:1252-1258

15. Sjöberg K, Lepers JP, Raharimalala L, Larsson A, Olerup O, Marbiah NT, Troye-Blomberg M, Perlmann P: Genetic regulation of human anti-malarial antibodies in twins. Proc Natl Acad Sci USA 1992, 89:2101-2104.

16. Aucan $C$, Traoré $Y$, Fumoux $F$, Rihet $P$ : Familial correlation of immunoglobulin $\mathrm{G}$ subclass responses to Plasmodium falciparum antigens in Burkina Faso. Infect Immun 2001, 69:996-1001.

17. Jepson A: Quantification of the relative contribution of major histocompatibility complex (MHC) and non-MHC genes to human immune responses to foreign antigens. Infect Immun 1997, 65:872-876.

18. Stirnadel HA, Beck HP, Alpers MP, Smith TA: Heritability and segregation analysis of immune responses to specific malaria antigens in Papua New Guinea. Genet Epidemiol 1999, 17:16-34

19. Modiano D, Chiucchiuini A, Petrarca V, Sirima BS, Luoni G, Perlmann H, Esposito F, Coluzzi M: Humoral response to Plasmodium falciparum Pf155/ ring-infected erythrocyte surface antigen and Pf332 in three sympatric ethnic groups of Burkina Faso. Am J Trop Med Hyg 1998, 58:220-224.

20. Tangteerawatana P, Perlmann H, Hayano M, Kalambaheti T, Troye-Blomberg M, Khusmith S: IL4 gene polymorphism and previous malaria experiences manipulate anti-Plasmodium falciparum antibody isotype profiles in complicated and uncomplicated malaria. Malar J 2009, 8:286.

21. Cabrera G, Cot M, Migot-Nabias F, Kremsner PG, Deloron P, Luty AJF: The sickle cell trait is associated with enhanced immunoglobulin $\mathrm{G}$ antibody responses to Plasmodium falciparum variant surface antigens. J Infect Dis 2005, 191:1631-1638.

22. Ntoumi F, Flori L, Mayengue PI, Matondo Maya DW, Issifou S, Deloron P, Lell B, Kremsner $P G$, Rihet $P$ : Influence of carriage of hemoglobin $A S$ and the $F c$ gamma receptor lla-R131 allele on levels of immunoglobulin G2 antibodies to Plasmodium falciparum merozoite antigens in Gabonese children. $J$ Infect Dis 2005, 192:1975-1980.

23. Israelsson E, Vafa M, Maiga B, Lysén A, Iriemenam NC, Dolo A, Doumbo OK, Troye-Blomberg M, Berzins K: Differences in Fcgamma receptor lla genotypes and IgG subclass pattern of anti-malarial antibodies between sympatric ethnic groups in Mali. Malar J 2008, 7:175

24. Migot-Nabias F, Mombo LE, Luty AJ, Dubois B, Nabias R, Bisseye C, Millet $P$, Lu CY, Deloron P: Human genetic factors related to susceptibility to mild malaria in Gabon. Genes Immun 2000, 1:435-441.

25. Carpenter D, Rooth I, Färnert A, Abushama H, Quinnell RJ, Shaw M-A: Genetics of susceptibility to malaria related phenotypes. Infect Genet Evol 2009, 9:97-103.

26. Rihet $P$, Flori $L$, Tall F, Traore AS, Fumoux F: Hemoglobin $C$ is associated with reduced Plasmodium falciparum parasitemia and low risk of mild malaria attack. Hum Molec Genet 2004, 13:1-6.

27. Rihet $P$, Traoré $Y$, Abel L, Aucan C, Traoré-Leroux T, Fumoux F: Malaria in humans: Plasmodium falciparum blood infection levels are linked to chromosome 5q31-q33. Am J Hum Genet 1998, 63:498-505.

28. Zhang L, Cui X, Schmitt K, Hubert R, Navidi W, Arnheim N: Whole genome amplification from a single cell: implications for genetic analysis. Proc Natl Acad Sci USA 1992, 89:5847-5851. 
29. Atkinson A, Barbier M, Afridi S, Fumoux F, Rihet P: Evidence for epistasis between hemoglobin $C$ and immune genes in human $P$. falciparum malaria: a family study in Burkina Faso. Genes Immun 2011, 12:481-489.

30. Barbier M, Atkinson A, Fumoux F, Rihet P: IL12B polymorphisms are linked but not associated with Plasmodium falciparum parasitemia: a familial study in Burkina Faso. Genes Immun 2008, 9:405-411.

31. Jiang XM, Arepally G, Poncz M, McKenzie SE: Rapid detection of the Fc gamma RIIA-H/R 131 ligand-binding polymorphism using an allele-specific restriction enzyme digestion (ASRED). J Immunol Meth 1996, 199:55-59.

32. Laird NM, Horvath S, Xu X: Implementing a unified approach to familybased tests of association. Genet Epidemiol 2000, 19(Suppl 1):S36-S42.

33. Storey JD, Tibshirani R: Statistical significance for genomewide studies. Proc Natl Acad Sci USA 2003, 100:9440-9445

34. Tangteerawatana P, Montgomery SM, Perlmann H, Looareesuwan S, TroyeBlomberg M, Khusmith S: Differential regulation of IgG subclasses and IgE antimalarial antibody responses in complicated and uncomplicated Plasmodium falciparum malaria. Parasite Immunol 2007, 29:475-483.

35. Dodoo D, Aikins A, Kusi KA, Lamptey H, Remarque E, Milligan P, Bosomprah S, Chilengi R, Osei YD, Akanmori BD, Theisen M: Cohort study of the association of antibody levels to AMA1, MSP119, MSP3 and GLURP with protection from clinical malaria in Ghanaian children. Malar J 2008, 7:142.

36. Fujieda S, Zhang K, Saxon A: IL-4 plus CD40 monoclonal antibody induces human B cells gamma subclass-specific isotype switch: switching to gamma 1, gamma 3, and gamma 4, but not gamma 2. J Immunol 1995, 155:2318-2328.

37. Kawano Y, Noma T, Kou K, Yoshizawa I, Yata J: Regulation of human IgG subclass production by cytokines: human IgG subclass production enhanced differentially by interleukin-6. Immunology 1995, 84:278-284

38. Garraud O, Perraut R, Diouf A, Nambei WS, Tall A, Spiegel A, Longacre S, Kaslow DC, Jouin H, Mattei D, Engler GM, Nutman TB, Riley EM, MercereauPuijalon O: Regulation of antigen-specific immunoglobulin $\mathrm{G}$ subclasses in response to conserved and polymorphic Plasmodium falciparum antigens in an in vitro model. Infect Immun 2002, 70:2820-2827.

39. Malisan F, Brière F, Bridon JM, Harindranath N, Mills FC, Max EE, Banchereau J, Martinez-Valdez H: Interleukin-10 induces immunoglobulin G isotype switch recombination in human CD40-activated naive B lymphocytes. J Exp Med 1996, 183:937-947.

40. Kawano Y, Noma T, Yata J: Regulation of human IgG subclass production by cytokines. IFN-gamma and IL- 6 act antagonistically in the induction of human IgG1 but additively in the induction of IgG2. J Immunol 1994, 153:4948-4958.

41. Servet-Delprat C, Bridon JM, Djossou O, Yahia SA, Banchereau J, Briere F: Delayed IgG2 humoral response in infants is not due to intrinsic $T$ or $B$ cell defects. Int Immunol 1996, 8:1495-1502.

42. Williams TN, Mwangi TW, Roberts DJ, Alexander ND, Weatherall DJ, Wambua S, Kortok M, Snow RW, Marsh K: An immune basis for malaria protection by the sickle cell trait. PLoS Med 2005, 2:e128.

43. Storey J, Fleming AF, Cornille-Brøgger R, Molineaux L, Matsushima T, Kagan I: Abnormal haemoglobins in the Sudan savanna of Nigeria. IV. Malaria, immunoglobulins and antimalarial antibodies in haemoglobin AC individuals. Ann Trop Med Parasitol 1979, 73:311-315.

44. Verra F, Simpore J, Warimwe GM, Tetteh KK, Howard T, Osier FHA, Bancone G, Avellino P, Blot I, Fegan G, Bull PC, Williams TN, Conway DJ, Marsh K, Modiano D: Haemoglobin $C$ and $S$ role in acquired immunity against Plasmodium falciparum malaria. PLoS One 2007, 2:e978.

45. Deloron P, Dubois B, Le Hesran JY, Riche D, Fievet N, Cornet M, Ringwald P, Cot M: Isotypic analysis of maternally transmitted Plasmodium falciparum-specific antibodies in Cameroon, and relationship with risk of P. falciparum infection. Clin Exp Immunol 1997, 110:212-218.

46. Oeuvray C, Theisen M, Rogier C, Trape JF, Jepsen S, Druilhe P: Cytophilic immunoglobulin responses to Plasmodium falciparum glutamate-rich protein are correlated with protection against clinical malaria in Dielmo, Senegal. Infect Immun 2000, 68:2617-2620.

47. Nasr A, Iriemenam NC, Giha HA, Balogun HA, Anders RF, Troye-Blomberg M, ElGhazali G, Berzins K: FcyRlla (CD32) polymorphism and anti-malarial lgG subclass pattern among Fulani and sympatric ethnic groups living in eastern Sudan. Malar J 2009, 8:43.

48. Shashidharamurthy R, Zhang F, Amano A, Kamat A, Panchanathan R, Ezekwudo D, Zhu C, Selvaraj P: Dynamics of the interaction of human IgG subtype immune complexes with cells expressing $\mathrm{R}$ and $\mathrm{H}$ allelic forms of a low-affinity Fc gamma receptor CD32A. J Immunol 2009, 183:8216-8224.
49. Nasr A, Iriemenam NC, Troye-Blomberg M, Giha HA, Balogun HA, Osman OF, Montgomery SM, ElGhazali G, Berzins K: Fc gamma receptor lla (CD32) polymorphism and antibody responses to asexual blood-stage antigens of Plasmodium falciparum malaria in Sudanese patients. Scand J Immunol 2007, 66:87-96.

50. Higuchi T, Seki N, Kamizono S, Yamada A, Kimura A, Kato H, Itoh K: Polymorphism of the 5 '-flanking region of the human tumor necrosis factor (TNF)-alpha gene in Japanese. Tissue Antigens 1998, 51:605-612.

51. Hohjoh $H$, Tokunaga $K$ : Allele-specific binding of the ubiquitous transcription factor OCT-1 to the functional single nucleotide polymorphism (SNP) sites in the tumor necrosis factor-alpha gene (TNFA) promoter. Genes Immun 2001, 2:105-109.

52. Boussiotis VA, Nadler LM, Strominger JL, Goldfeld AE: Tumor necrosis factor alpha is an autocrine growth factor for normal human B cells. Proc Natl Acad Sci USA 1994, 91:7007-7011.

doi:10.1186/1475-2875-11-308

Cite this article as: Afridi et al:: Malaria resistance genes are associated with the levels of IgG subclasses directed against Plasmodium falciparum blood-stage antigens in Burkina Faso. Malaria Journal 2012 11:308.

\section{Submit your next manuscript to BioMed Central and take full advantage of:}

- Convenient online submission

- Thorough peer review

- No space constraints or color figure charges

- Immediate publication on acceptance

- Inclusion in PubMed, CAS, Scopus and Google Scholar

- Research which is freely available for redistribution

Submit your manuscript at www.biomedcentral.com/submit
C) Biomed Central 